\title{
Study of drug utilization, morbidity pattern and cost of hypolipidemic agents in a tertiary care hospital
}

\author{
Kamlesh P. Patel ${ }^{1}$, Harsh M. Joshi ${ }^{1}$, Chintan Khandhedia ${ }^{2}$, Harsh Shah ${ }^{1}$, \\ Kartik N. Shah ${ }^{1}$, Varsha J. Patel ${ }^{1}$
}

\begin{abstract}
${ }^{1}$ Department of Pharmacology, Smt. N.H.L. Municipal Medical College, Ellisbridge, Ahmedabad -380 006, India ${ }^{2}$ Medical Services Department, Intas Pharmaceuticals, Chinubhai Centre, Ashram Road, Ahmedabad, India

Received: 17 June 2013

Accepted: 28 June 2013

\section{*Correspondence to:}

Dr. Kamlesh P. Patel,

Email:

drkamleshp@yahoo.com

(C) 2013 Patel KP et al. This is an open-access article distributed under the terms of the Creative Commons Attribution License, which permits unrestricted use, distribution, and reproduction in any medium, provided the original work is properly cited.
\end{abstract}

\begin{abstract}
Background: Data on the extent of use and costs of lipid-lowering agents are not widely available. Our aim was to study the drug utilization and morbidity pattern, cost of different hypolipidemic drugs along with the risk assessment for coronary heart disease.

Methods: After approval of protocol by the Institutional Review Board, an observational, prospective study was carried out in 300 patients using NCEP and ATP III Guidelines-2002 for evaluation of presence or absence of risk factors for coronary heart diseases. Data were analysed using SPSS software version 16.0and WHO Core Drug Prescribing Indicators.

Results: Patient's morbidity pattern revealed that $62 \%, 49.3 \%, 28 \%$ suffered from ischemic heart disease, hypertension and type 2 diabetes mellitus respectively. On risk assessment, 48\%, 13.3\% patients had borderline and high level of total cholesterol respectively; 42\%, 22.7\% had borderline and high triglyceride levels respectively; $71.1 \%$ men and $62 \%$ women had low HDL cholesterol levels while $17.3 \%, 6 \%$ and $2.7 \%$ patients had borderline high, high and very high level of LDL cholesterol levels respectively. Frequency of prescriptions was atorvastatin $(82 \%)$, rosuvastatin $(9.3 \%)$ and simvastatin $(4.7 \%)$ among the most frequently prescribed statins drug group. The mean number of drugs per prescription was 7.34. Drugs prescribed by generic name and from essential drugs list was $24.96 \%$ and $71.81 \%$ respectively. Mean cost of hypolipidemic agents/prescription/day was 10.74 ( \pm 1.96$)$ Indian Rupees with rosuvastatin being the costliest.
\end{abstract}

Conclusion: Rational use of hypolipidemic agents with an increasing trend of statins prescriptions will significantly reduce the morbidity and mortality from coronary heart diseases.

Keywords: Coronary heart disease, Dyslipidemia, Hypolipidemic agents, Statins

\section{INTRODUCTION}

In India, Cardiovascular diseases (CVD) is projected to be the largest cause of death and disability by 2020 with 2.6 million. Indians are predicted to die due to coronary heart diseases, which constitutes $54.1 \%$ of all CVD deaths. It is estimated that, nearly half of these deaths are likely to occur among young and middle-aged individuals (30-79 years). This is because Indians experience CVD deaths at least a decade before their counterparts in the developed countries. ${ }^{1}$

Currently, lipid-lowering agents are widely used to reduce the risk of coronary events. However, there is wide variation in the selection and use of lipid-lowering agents. ${ }^{2,3}$ Data on the extent of use and costs of lipid- lowering agents are not widely available. Moreover, guidelines for management of dyslipidemia released by the U.S., National Cholesterol Education Program $(\mathrm{NCEP})^{4}$ have been questioned for their relevance in Indian populations because these populations are reported to have significantly different lipoprotein parameters and atherogenic risk factors than Western populations. ${ }^{5}$

Therefore, studies on the prescription pattern and costs of these drugs, particularly in our country are needed to better support decision making processes (from individual clinical setting to the wider national regulatory or public health settings). Hence, our objective was to study the utilization and morbidity pattern, and cost of different hypolipidemic drugs in hospitalized patients along with the risk assessment for coronary heart disease. 


\section{METHODS}

A prospective and observational study was carried out in 300 patients of either sex at a medicine outpatient department (OPD) at a tertiary care teaching hospital in Ahmedabad, India during 12 months period from June 2010 to May 2011. Patients who were prescribed any of the hypolipidemic medications irrespective of clinical condition either as monotherapy or in combination with other agents were included in the study. The study protocol, proforma, patient information sheet and informed consent form were approved by Institutional Review Board (IRB). All the patients were evaluated for presence or absence of risk factors for Coronary Heart Disease (CHD) based on the Third report of National Cholesterol Education Program (NCEP) - The Expert Panel; Adult Treatment Panel (ATP) III Guidelines-2002. The morbidity pattern and the risk assessment were studied by analysing the data of the patients collected in a pre-designed proforma which included patient's demographic details, presenting complaints, past and family history, co-morbidity, provisional diagnosis, laboratory investigations and complete prescription. The mean number of drugs per prescription, percentage of drugs prescribed by generic name and percentage of drugs prescribed from essential drugs list were analysed using WHO Core Drug Prescribing Indicators. Since, majority of the patients often required long-term or lifelong therapy with hypolipidemic drugs, monthly cost of the drug was determined. Analysis of prescriptions containing hypolipidemic drugs was done using SPSS software version 16.0.

\section{RESULTS}

Demographic pattern of the 300 patients enrolled in a one year study revealed that $166(55.33 \%)$ were males and 134 (44.67\%) were females. Majority of males and females were in the age group of 40-69 years and 50-79 years with mean age of $55.19( \pm 11.11)$ years and 57.18 $( \pm 11.67)$ years respectively. The demographic data demonstrated the influence of gender and age in disease and prescription pattern.

Morbidity patterns demonstrated that majority of the patients were diagnosed with ischemic heart disease which includes angina / myocardial infarction $(62 \%)$ followed by hypertension (49.3\%), type II diabetes mellitus (28\%) and other diseases like stroke $(5 \%)$, acute heart failure $(9 \%)$, hypothyroidism (9\%), complete heart block (6\%), peripheral vascular disease $(1 \%)$, osteoporosis $(1 \%)$, acute renal failure $(1 \%)$ and epitasis $(3 \%)$. This suggests that one patient may present with more than one diseases (Figure 1). Majority of the patients presented with complaints of chest pain (86\%) followed by gabhraman (36\%), perspiration (26.7\%), gastrointestinal (18.7\%) and respiratory tract complaints $(13.3 \%)$.

All the patients were evaluated for risk of Coronary Heart Diseases (CHD). based on the Third Report of the
National Cholesterol Education Program (NCEP) - The Expert Panel, Adult Treatment Panel (ATP) III Guidelines-2002.On identifying the level of risk factors, it was found that $77.2 \%$ males and $47.8 \%$ females were more than 45 years and 55 years of age respectively. $10.67 \%$ had history of CHD, $25.4 \%$ patients were smokers with or without tobacco chewing and $67.34 \%$ patients had low level of HDL cholesterol (Table 1).

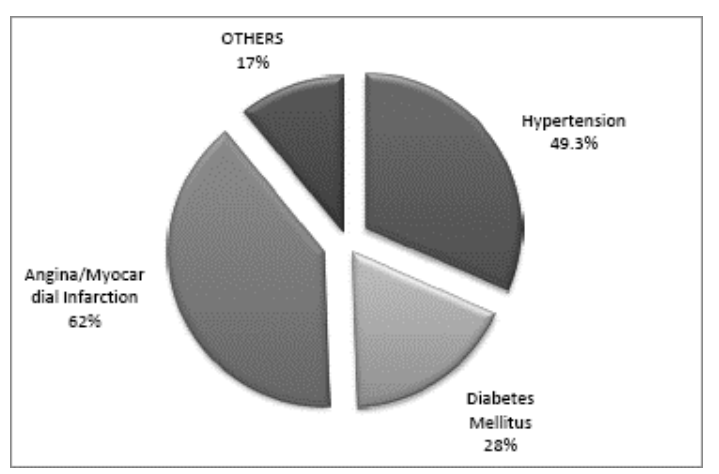

Figure 1: Morbidity pattern.

Note: One Patient may have more than one diseases.

Table 1: Risk factors for ischemic heart disease.

\begin{tabular}{|lll|}
\hline Sr. No. & Risk factors & No. of patients $(\%)$ \\
\hline & Age & \\
& $\begin{array}{l}\text { Male }>45 \mathrm{yr} \\
\text { Female }>55 \mathrm{yr}\end{array}$ & $\begin{array}{l}232(77.20 \%) \\
143(47.80 \%)\end{array}$ \\
\hline 2 & History of CHD & $32(10.67 \%)$ \\
\hline 3 & Smoking & $76(25.40 \%)$ \\
\hline 4 & $\begin{array}{l}\text { Low HDL } \\
\text { Male <40 mg/dL }\end{array}$ & $202(67.34 \%)$ \\
\hline 5 & Female <50 mg/dL & $148(49.30 \%)$ \\
\hline 6 & $\begin{array}{l}\text { Hypertension } \\
\text { Type II diabetes }\end{array}$ & $84(28 \%)$ \\
\hline
\end{tabular}

The mean Baseline Plasma Lipid levels (mg/dL) were carried out in all patients. Lipid profile revealed mean $( \pm$ SD) level of total cholesterol $207.13( \pm 29.1) \mathrm{mg} / \mathrm{dL}$ which was borderline high, triglycerides $161.62( \pm 47.1)$ $\mathrm{mg} / \mathrm{dL}$ which was borderline high, HDL-C $41.5( \pm 14.4)$ $\mathrm{mg} / \mathrm{dL}$ which was low for women, LDL-C $110.63( \pm 31.4)$ $\mathrm{mg} / \mathrm{dL}$ which was near optimal and VLDL-C 40.97 $( \pm 13.3) \mathrm{mg} / \mathrm{dL}$ (Table 2). On risk assessment, it was found that $48 \%$ and $13.3 \%$ patients had borderline and high level of total cholesterol respectively; $42 \%$ and $22.7 \%$ had borderline and high triglyceride levels respectively; $71.1 \%$ men and $62 \%$ women had low HDL cholesterol levels while $17.3 \%, 6 \%$ and $2.7 \%$ patients had borderline high, high and very high level of LDL cholesterol levels respectively (Table 3). 
Table 2: Mean baseline plasma lipid level (mg/dL).

\begin{tabular}{|ll|}
\hline LIPID Parameters & Mean $( \pm$ SD $)$ \\
\hline Total Cholesterol & $207.13( \pm 29.1)$ \\
\hline Triglycerides & $161.62(47.1)$ \\
\hline HDL - C & $41.5( \pm 14.4)$ \\
\hline LDL $-C$ & $110.63( \pm 31.4)$ \\
\hline VLDL $-C$ & $40.97( \pm 13.3)$ \\
\hline
\end{tabular}

Table 3: Risk assessment based on plasma lipid level.

\begin{tabular}{|ll|l|}
\hline $\begin{array}{l}\text { Plasma Lipid } \\
\text { Level (mg/dL) }\end{array}$ & Comments & $\begin{array}{l}\text { No. of } \\
\text { Patients }(\%)\end{array}$ \\
\hline $\begin{array}{l}\text { Total } \\
\text { Cholesterol } \\
<200\end{array}$ & & \\
$200-239$ & Desirable & $116(38.7 \%)$ \\
$>240$ & Borderline High & $144(48.0 \%)$ \\
\hline $\begin{array}{l}\text { Triglycerides } \\
<150\end{array}$ & High & $40(13.3 \%)$ \\
$150-199$ & Normal & $106(35.3 \%)$ \\
$200-499$ & Borderline High & $126(42.0 \%)$ \\
$>500$ & High & $68(22.7 \%)$ \\
\hline $\begin{array}{l}\text { HDL }-\mathbf{C} \\
<40\end{array}$ & Very High & --------- \\
$<50$ & Low (Men) & $118(71.1 \%)$ \\
\hline $\begin{array}{l}\text { LDL }- \text { C } \\
<70\end{array}$ & Low (Women) & $84(62.7 \%)$ \\
\hline & Optimal for very & $20(6.70 \%)$ \\
$<100$ & high risk & \\
$<100-129$ & Optimal & $102(34.0 \%)$ \\
$130-159$ & Near optimal & $120(40.0 \%)$ \\
$160-189$ & Borderline High & $52(17.3 \%)$ \\
$>190$ & High & $18(6.0 \%)$ \\
\hline & Very High & $8(2.7 \%)$ \\
\hline
\end{tabular}

Ref: Third Report of the National Cholesterol Education Program (NCEP) - The Expert Panel, Adult Treatment Panel (ATP) III Guidelines-2002.

Total 2203 drug formulations were distributed among 300 prescriptions. Apart from hypolipidemic agents, patients were prescribed concomitant drugs based on morbidity patterns. On prescription analysis, it was revealed that $96 \%$ of the patients received statins. Fibric acid derivatives (Fenofibrate) and Cholesterol absorption inhibitors (Ezetimibe) were used rarely (4\%) and only in combination with statin in patients with severe dyslipidemia not controlled by statin monotherapy. Among statins, atorvastatin (82\%) was most commonly prescribed, followed by rosuvastatin (9.3\%) and simvastatin (4.7\%) (Figure 2). Apart from hypolipidemic agents, concomitant drugs used were antiplatelets (96.7\%), nitrates $(88.3 \%)$, beta blockers $(79.3 \%)$, ACE inhibitors/ARBs (75.6\%), anticoagulants (62.3\%), fibrinolytics $(49.3 \%)$, diuretics $(35.4 \%)$, calcium channel blockers $(15.0 \%)$, oral hypoglycemic agents $(27.6 \%)$ and insulin $(5.3 \%)$. This suggests that one patient may had taken more than one drug because majority of the study populations had one or more risk factors.

As majority of the patients often require long-term or life-long therapy with hypolipidemic agents, monthly cost were analysed. The mean cost of hypolipidemic agents / prescription / day was 10.74 ( \pm 1.96) INR (Indian Rupees) with rosuvastatin being the costlier (Table 4).

Table 4: Cost of various hypolipidemic agents.

\begin{tabular}{|c|c|}
\hline Drug & $\begin{array}{l}\text { Total Cost/month } \\
\text { (INR) } \\
\text { Mean } \pm \text { SD }\end{array}$ \\
\hline $\begin{array}{r}\text { Atorvastatin }-10 \mathrm{mg} \\
20 \mathrm{mg} \\
40 \mathrm{mg} \\
\text { Mean }\end{array}$ & $\begin{array}{l}187 \pm 11.3 \\
362.89 \pm 11.2 \\
468 \pm 12.2 \\
327.3 \pm 11.4\end{array}$ \\
\hline $\begin{array}{r}\text { Rosuvastatin }-5 \mathrm{mg} \\
10 \mathrm{mg} \\
20 \mathrm{mg} \\
\text { Mean }\end{array}$ & $\begin{array}{l}186 \pm 22.2 \\
447.7 \pm 20.5 \\
795 \pm 45.7 \\
422.7 \pm 43.5\end{array}$ \\
\hline $\begin{array}{r}\text { Simvastatin }-10 \mathrm{mg} \\
20 \mathrm{mg} \\
\text { Mean }\end{array}$ & $\begin{array}{l}174 \pm 33.5 \\
335 \pm 11.5 \\
312 \pm 56.7\end{array}$ \\
\hline $\begin{array}{l}\text { Atorvastatin+Ezetimibe } \\
(10 \mathrm{mg}+10 \mathrm{mg})\end{array}$ & $304.8 \pm 3.5$ \\
\hline $\begin{array}{l}\text { Atorvastatin }+ \text { Fenofibrate } \\
(10 \mathrm{mg}+10 \mathrm{mg})\end{array}$ & 327 \\
\hline $\begin{array}{l}\text { Simvastatin + Ezetimibe } \\
(10 \mathrm{mg}+10 \mathrm{mg})\end{array}$ & 240 \\
\hline
\end{tabular}

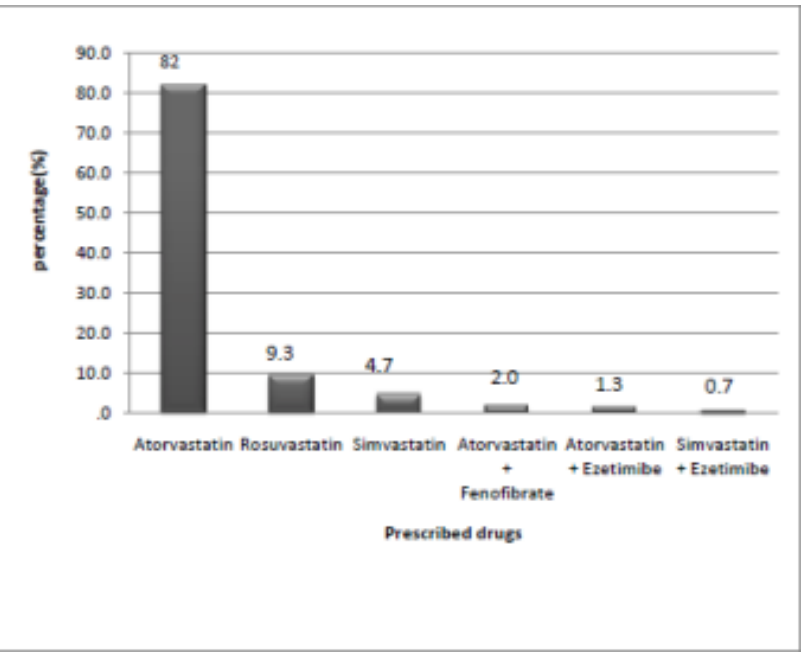

Figure 2: Prescription of hypolipidemic agents.

The mean number of drugs per prescription according to WHO Core Drug Prescribing Indicators were found to be $7.34 \pm 1.4$ in our study. The percentage of drugs prescribed by generic name was $24.96 \%$. Percentage of 
drugs prescribed from essential drugs list was $71.81 \%$ (Table 5).

Table 5: WHO core drug prescribing indicators.

\begin{tabular}{|lll|}
\hline Sr. No. & Indicator & Value \\
\hline 1. & $\begin{array}{l}\text { Mean }( \pm \text { SD) number of } \\
\text { drugs per prescription }\end{array}$ & $7.34( \pm 1.4)$ \\
\hline 2. & $\begin{array}{l}\text { Percentage of drugs } \\
\text { prescribed by generic } \\
\text { name }\end{array}$ & 24.96 \\
\hline $3 . \quad \begin{array}{l}\text { Percentage of } \\
\text { encounters with } \\
\text { antibiotic prescribed }\end{array}$ & 23.67 \\
\hline 4. & $\begin{array}{l}\text { Percentage of } \\
\text { encounters with an } \\
\text { injection prescribed }\end{array}$ \\
\hline & $\begin{array}{l}\text { Percentage of drugs } \\
\text { prescribed from } \\
\text { essential drug list }\end{array}$ \\
\hline
\end{tabular}

\section{DISCUSSION}

In the present study, the demographic data demonstrated that baseline study population was comparable to earlier studies done in India and abroad with an influence of gender and age in prescription patterns, as reported in other studies. ${ }^{6,7}$ In our study males $(55.33 \%)$ were more on hypolipidemic therapy compared to females $(44.67 \%)$ which may be due to the contributing risk factors like smoking, alcohol intake, diet rich in saturated fat seen commonly in males in India. The findings are in accordance with the study carried out in Hyderabad. ${ }^{8}$ Majority of males and females were in the age group of 40-69 years and 50-79 years respectively which is in accordance with the study carried out in Mumbai. ${ }^{9}$ This was not surprising since the risk of Coronary Heart Disease (CHD) is high in this age group.

On identifying the level of risk factors it was found that majority of the study populations had one or more risk factors which are associated with increased risk of CHD event. Apart from risk factors for CHD, assessment of plasma lipids was essential to guide and monitor the treatment. Therefore, Mean Baseline Plasma Lipid levels $(\mathrm{mg} / \mathrm{dL})$ were carried out in all patients. Lipid profile revealed that mean $( \pm$ SD) level of total cholesterol 207.13 $( \pm 29.1) \mathrm{mg} / \mathrm{dL}$ which was borderline high, triglycerides $161.62( \pm 47.1) \mathrm{mg} / \mathrm{dL}$ which was borderline high, HDLC $41.5( \pm 14.4) \mathrm{mg} / \mathrm{dL}$ which was low for women, LDL-C $110.63( \pm 31.4) \mathrm{mg} / \mathrm{dL}$ which was near optimal and VLDL-C $40.97( \pm 13.3) \mathrm{mg} / \mathrm{dL}$. On risk assessment, it was found that $48 \%$ and $13.3 \%$ patients had borderline and high level of total cholesterol respectively, $42 \%$ and $22.7 \%$ had borderline and high triglyceride levels respectively, $71.1 \%$ men and $62.7 \%$ women had low HDL cholesterol levels while $17.3 \%, 6 \%$ and $2.7 \%$ patients had borderline high, high and very high level of LDL cholesterol levels respectively. The findings are in accordance with the study carried out in North India. Thus, risk assessment revealed that majority of the patients were at risk of developing CHD, thereby requiring lipid-lowering treatment prior to development of clinical CHD.

The prescription analysis of hypolipidemic agents revealed that $96 \%$ of the patients received statins. Fenofibrate and Ezetimibe were used rarely (4\%) and only in combination with statins in patients with severe dyslipidemia not controlled by statin monotherapy. Among statins, atorvastatin (82\%) was most commonly used, followed by rosuvastatin $(9.3 \%)$ and simvastatin $(4.7 \%)$. Similar prescription patterns were found in studies carried out in European countries ${ }^{10}$ and Indian cities such as Jaipur ${ }^{11}$ and Hyderabad. ${ }^{8}$ This suggests a more rational use of hypolipidemic agents with a higher prescription of first-line drugs for the treatment of dyslipidemia - statins. This is recommended as the most effective and better tolerated therapy for lowering LDL-C - together with the reduced use of older, less effective drugs. ${ }^{12}$ Several trials have indicated that cholesterol lowering therapy with statins reduces the numbers of coronary deaths and nonfatal myocardial infarctions. ${ }^{13,14}$ Thus active treatment of hypercholesterolemia significantly reduces the risk of morbidity and mortality from CHD.

Apart from hypolipidemic agents, patients were prescribed concomitant drugs such as antiplatelets (96.7\%), nitrates (88.3\%), beta-blockers (79.4\%), ACE- inhibiters / Angiotensin Receptor Blockers (75.6\%), anticoagulants $(62.3 \%)$, fibrinolytics $(49.3 \%)$, oral hypoglycaemic agents $(27.6 \%)$ which can be justified, as the prevalence of ischemic heart disease (62\%), hypertension $(49.3 \%)$ and type II diabetes mellitus (28\%) were high in the present study population. The findings are in accordance with the studies carried out in North America, ${ }^{15}$ Indian CREATE registry, ${ }^{16}$ Jaipur $^{11}$ and Mangalore. ${ }^{17}$

The cost analysis revealed that the mean cost of hypolipidemic agents / prescription / day was 10.74 ( \pm 1.96) INR (Indian Rupees) which was higher than the study carried out in Mangalore, ${ }^{17}$ This could be because of promoting and prescribing drugs by brand names $(75.04 \%)$. Rosuvastatin was costlier as compared to other statins prescribed alone or in combination. The practice of prescribing drugs with generic names or choosing less expensive brands should be encouraged which will be cost-effective.

Average number of drugs per prescription is an important index of clinical judgement of the prescribers and intervention in prescribing practices. According to WHO core drug prescribing indicators, the mean number of drugs per prescription were found to be $7.34 \pm 1.4$ in our study, which are comparable to the studies conducted in Brazil (8.6) and Hyderabad (5.5) suggesting 
polypharmacy. However, in certain conditions like cardiovascular problems, the patients may require more than one drug. 8,18

Moreover, percentage of drugs prescribed by generic names were only $24.96 \%$ suggesting greater tendency to prescribe drugs by brand names which may be due to greater influence of the pharmaceutical companies on the prescribing habits thereby increasing the cost of therapy. Percentage of drugs prescribed from essential drugs list were $71.81 \%$. This suggests that the compliance of the patient may be better due to availability of drugs at affordable price.

\section{CONCLUSION}

The study depicts that over-all prescribing habit in this set-up is appropriate and rational to a large extent. Only step-back is the lesser number of drugs prescribed by generic name suggesting need for sincere efforts to improve situation. The use of statins was higher in the study which is recommended as the most effective and better tolerated first-line therapy for dyslipidemia. Such a rational use of hypolipidemic will significantly reduce the morbidity and mortality from coronary heart disease. This is the preliminary study and further studies are required to find out broader evaluation of the hypolipidemic agents. Hence, such periodic studies are further required in diverse environment, social, educational and cultural conditions, so that the therapeutic guidelines could be revised accordingly to give proper care to the community.

\section{ACKNOWLEDGEMENTS}

We are highly thankful to our Dean Dr. Pankaj Patel and Head of Department of Medicine Dr. Sundeep Malhan for permitting us to carry out the study and collect data.

\section{Funding: None}

Conflict of Interest: None declared

Ethical approval: The study was approved by the Institutional Review Board

\section{REFERENCES}

1. Prabhakaran D, Yusuf S, Mehta S, Pogue J, Avezum A, Budaj A, et al. Two-year outcomes in patients admitted with non-ST elevation acute coronary syndrome: results of the OASIS registry 1 and 2 . Indian Heart J 2005;57(3):217-25.

2. Siegel D, Lopez J, Meier J. Use of cholesterollowering medications in the United States from 1991 to 1997. American Journal of Medicine 2000;108:496-9.

3. Walley T, Folino-Gallo P, Stephens P, Van Ganse E. Trends in prescribing and utilization of statins and other lipid lowering drugs across Europe 1997 2003. British Journal of Clinical Pharmacology, 2005,60:543-51.
4. Third Report of the National Cholesterol Education Program (NCEP) Expert Panel on Detection, Evaluation, and Treatment of High Blood Cholesterol in Adults (Adult Treatment Panel III). Journal of American Medical Association (JAMA) 2001;285:2486-97.

5. Goyal Pankaj, Geeta Sharma, Baljinderpal S, et al. Prospective, non-interventional, uncontrolled, openchart, pharmacoepidemiologic study of prescribing patterns for lipid-lowering drugs at a tertiary care teaching hospital in North India. Clinical Therapeutics 2002;24(12):2064-76.

6. Sleator DJ. Towards accurate prescribing analysis in general practice: accounting for the effects of practice demography. British Journal of Clinical Pharmacology 1993;43:102-6.

7. Roe C, McNamara A, Motheral B. Gender and agerelated prescription drug use patterns. Annals of Pharmacotherapy 2002;36:30-9.

8. Fareedullah Md, Sreedevi K, Venkateswara Rao J, Vijayakumar S. A study on prescription pattern of statins in cardiovascular disease. Scholars Research Library Der Pharmacia Lettre 2011;3(3):393-6.

9. Pillai PG, P. Suresh, Gayatri Aggarwal, Gaurav Doshi, Vidhi Bhatia, Harsha Kathpalia. Studies on the prescriptions of cardio vascular units. Journal of Applied Pharmaceutical Science 2011;1(3):128-31.

10. EURO-MED-STAT, 2006. Available at http://www. euromedstat.cnr.it/database/time1.asp. Accessed 25 February 2013.

11. Krishna K Sharma, Rajeev Gupta, Aachu Agrawal, Sanjeeb Roy, Atul Kasliwal, Ajeet Bana, et al. Low use of statins and other coronary secondary prevention therapies in primary and secondary care in India. Vascular Health and Risk Management 2009;5:1007-14.

12. De Backer G, Ambrosioni E, Borch-Johnsen K, et al European guidelines on cardiovascular disease prevention in clinical practice. Third Joint Task Force of European and Other Societies on Cardiovascular Disease Prevention in Clinical Practice. European Heart J 2003,24:1601-10.

13. Sacks FM, Pfeffer MA, Moye LA, Rouleau JL, Rutherford JD, Cole TG, et al. The effect of pravastatin on coronary events after myocardial infarction in patients with average cholesterol levels. Cholesterol and Recurrent Events Trial investigators. N Engl J Med. 1996 Oct 3;335(14):1001-9.

14. Scandinavian Simvastatin Survival Study Group. Randomised trial of cholesterol lowering in 4444 patients with coronary heart disease: the Scandinavian Simvastatin Survival Study (4S). Lancet. 1994 Nov 19;344(8934):1383-9.

15. Gibson CM. NRMI and current treatment patterns for ST-elevation myocardial infarction. Am Heart J. 2004 Nov;148(5 Suppl):S29-33.

16. Xavier D, Pais P, Devereaux PJ, Xie C, Prabhakaran $\mathrm{D}$, Reddy KS, et al. Treatment and outcomes of acute coronary syndromes in India (CREATE): a 
prospective analysis of registry data. Lancet. 2008 Apr 26;371(9622):1435-42.

17. Rathnakar UP, Sheethal D. Ullal, Shruthi Sadanand, et al. Profile of Drug Utilization Among Elderly Patients Attending A Cardiology Clinic In
Mangalore, India Journal of Pharmacy Research. 2010;3(8):1835-7.

18. Victora CG, Facchini LA, Grassi Filho M. Drug usage in southern Brazilian hospitals. Trop Doct. 1982 Oct;12(4 Pt 2):231-5.

doi:10.5455/2319-2003.ijbcp20130823

Cite this article as: Patel KP, Joshi HM, Khandhedia C, Shah H, Shah KN, Patel VJ. Study of drug utilization, morbidity pattern and cost of hypolipidemic agents in a tertiary care hospital. Int $\mathbf{J}$ Basic Clin Pharmacol 2013;2:470-5. 